\title{
Evolution of acute toxicity of non-ionic surfactants over the biodegradation process
}

\author{
E. Jurado, M. Fernández-Serrano, J. Núñez, \\ M. Lechuga \& G. Luzón \\ Department of Chemical Engineering, University of Granada, Spain
}

\begin{abstract}
The present work examines the toxicity of two non-ionic surfactants widely used in current detergent formulations: a fatty-alcohol ethoxylate, Findet 1214N/23 $\left(\mathrm{R}\left(-\mathrm{O}-\mathrm{CH}_{2}-\mathrm{CH}_{2}\right)_{\mathrm{n}}-\mathrm{OH}: 70 \% \mathrm{C}_{12}\right.$ and $30 \% \mathrm{C}_{14} ; 11$ average ethylene oxide units) and nonylphenol polyethoxylate with 9.5 average ethylene oxide units. The biodegradation tests were made according to the OECD $301 \mathrm{E}$ test for ready biodegradability. These tests were made at different starting concentrations: 15 , 20, 25, and $50 \mathrm{mg} / \mathrm{L}$ for Findet $1214 \mathrm{~N} / 23$, and 5,25 , and $50 \mathrm{mg} / \mathrm{L}$ for nonylphenol polyethoxylate.

Toxicity was assessed with the LumiStox ${ }^{\circledR} 300$ system, consisting of an instrument for measuring bioluminescence and an incubation unit according to the UNE-EN ISO 11348-2 guideline. This method is based on the luminous intensity of marine bacteria of the strain Vibrio fisheri NRRL-B-11177 after a certain exposure time to a toxic substance. The toxicity value was calculated as $\mathrm{EC}_{50}$, which is the surfactant concentration that inhibits $50 \%$ after $15 \mathrm{~min}$ of exposure. Also, the change in toxicity was tracked during the biodegradation process in order to appraise the environmental risk posed by the products during this process. In these assays, the toxicity was expressed as a percentage of inhibition.
\end{abstract}

Keywords: toxicity, biodegradation, bioluminescent organisms, non-ionic surfactants.

\section{Introduction}

The detergent and cleaning-products industry in Spain represents more than 1620 million euros annually, generating thousands of jobs and producing some 1.8 
million tonnes of products per year, according to the A.D.T.A. (Association of Surfactant-Detergent Manufacturers; [1]). Regulation 1907/2006 of the European parliament concerning the registration, evaluation, authorization, and restriction of substances and prepared chemicals [2] establishes that by the year 2020 the substances that are manufactured and used must carry a minimization of significant adverse effects for human health and the environment.

Another aim of the European system under the present regulation is to foment and in certain cases guarantee that highly hazardous substances can be replaced by less harmful substances or technologies, when technically and economically viable. This regulation obligates companies to eliminate (whenever technologically possible) hazardous substances or replace them by others of lower environmental impact. Industrial cleaning products for general use are normally composed of aqueous solutions of surfactants with the addition of different coadjuvants, solvents, solubilizers, stabilizers, etc. Government control of these products, due to their widespread use, will be exhaustive in the near future. Current trends include the search for less environmentally aggressive alternatives that will be effective for cleaning as well as disinfecting [3].

Many types of bioassays are available to establish the toxicity levels of compounds for aquatic organisms, but many of these tests are also timeconsuming and not routinely applicable. Moreover, the use of higher organisms as test species may be ethically undesirable. Although several bioassays using microorganisms have been used, most of the bacterial screening tests have been based on luminiscence, because they are rapid, reproducible, simple to use, raise no ethical issues, and are cost-effective. One of these methods is the well-known Microtox ${ }^{\circledR}$ [4]. These assays provide a rapid response and, while not flawless, serve to compare different contaminants. In addition to providing assays with liophilized bacteria, these tests present high degrees of reproducibility, as demonstrated by interlaboratory tests. The speed, reliability, and normalization of these bioassays with luminescent bacteria make them suitable for establishing correlations between toxicity as well as the chemical structure and/or different properties of the compounds assayed.

The worldwide use of surfactants, which are generally dumped into water systems, requires them to be as inocuous as possible for the environment, i.e. of low toxicity and easy biodegradability. The comparison of different types of surfactants based on ecotoxicological and biodegradability tests can aid in selecting these compounds for detergent formulas. Given that intermediates result from primary biodegradation, ecotoxicity is monitored throughout the biodegradation process.

\section{Materials and methods}

The following surfactants were used in this study: a fatty-alcohol ethoxylate (Findet 1214N23) with the general formula $\mathbf{R}\left(-\mathbf{O}-\mathbf{C H}_{\mathbf{2}}-\mathbf{C H}_{\mathbf{2}}\right)_{\mathbf{n}}-\mathbf{O H}$ and a nonylphenol polyethoxylate (NPEO) with the general formula $\left(\mathbf{R}-\mathbf{C}_{6}-\mathbf{H}_{4}-\mathbf{O}-\right.$ $\left.\left(\mathrm{CH}_{2}-\mathbf{C H}_{2}-\mathbf{O}\right)_{9.5} \mathbf{H}\right)$, both supplied by KAO CORPORATION S.A. 
The measurement was taken with the LumiStox ${ }^{\circledR} 300$ system, which consists of an instrument for measuring bioluminescence and an incubation unit according to the UNE-EN ISO 11348-2 guideline [5]. The toxicity measurement is based on the luminous intensity of the marine bacteria Vibrio fisheri, strain NRRL-B-11177 after a certain exposure time to a toxic substance. The luminescent bacteria, dehydrated and frozen at $-18^{\circ} \mathrm{C}$, were reactivated with the suspension supplied by Dr. Lange. The assay conditions were $\mathrm{pH} 7.0$ and $\mathrm{CINa}$ concentration of $2 \%$. All the measurements were duplicated for incubations times of 15 and $30 \mathrm{~min}$. When necessary, the sample was filtered prior to the assay.

The toxicity value was measured as $\mathrm{EC}_{50}$ or $\mathrm{EC}_{20}$, which are, respectively, the surfactant concentrations that inhibit 50 and $20 \%$ after 15 and $30 \mathrm{~min}$ of exposure.

In addition, during the biodegradation process of the surfactant, a toxicity analysis was made of the evolution of the metabolites generated. The measurements were made following the same procedure indicated above. In this case, the results could not be expressed in terms of concentration, as the samples were of unknown composition. Therefore, to evaluate the toxicity during the biodegradation process the toxicity value of the sample is expressed as a percentage of inhibition, and the variation in toxicity during the biodegradation assay as the variation of the inhibition percentage [6]. The inhibitory effect of the samples assayed was calculated for an incubation time of $15 \mathrm{~min}$.

The biodegradation tests were carried out according to the OECD $301 \mathrm{E}$ test for ready biodegradability [7].

\section{Results and discussion}

The concentrations of the surfactant in the toxicity tests were $500 \mathrm{mg} / \mathrm{L}$. The initial values of luminous intensity measured were corrected by a factor that takes into account the natural decrease in luminous intensity, even in the absence of the toxic sample:

$$
\mathrm{f}_{\mathrm{k}}=\frac{\mathrm{I}_{\mathrm{t}}(0)}{\mathrm{I}_{0}(0)}
$$

with $\mathrm{I}_{0}(0)$ and $\mathrm{I}_{\mathrm{t}}(0)$ being the readings of luminous intensity in the well containing concentration 0 at time 0 and t eqn. 1 .

The percentage of inhibition (inhibitory effect) was calculated by the expression:

$$
\mathrm{H}_{\mathrm{t}}=\frac{\left(\mathrm{I}_{0 \mathrm{t}}(\mathrm{c})-\mathrm{I}_{\mathrm{t}}(\mathrm{c})\right)}{\mathrm{I}_{0 \mathrm{t}}(\mathrm{c})} 100
$$

where

$$
\mathrm{I}_{0 \mathrm{t}}(\mathrm{c})=\overline{\mathrm{f}_{\mathrm{k}}} \mathrm{I}_{0}(\mathrm{c})
$$


with $\mathrm{fk}$ being the average correction factor of the control samples, $\mathrm{I}_{0}(\mathrm{c})$ and $\mathrm{I}_{\mathrm{t}}(\mathrm{c})$ being the readings of luminous intensity in the well containing concentration $\mathrm{c}$ at time 0 and $t$. The Gamma function, the ratio between the light intensity lost by the bacterial solution and that remaining after exposure to the toxic sample, can be evaluated by the equation:

$$
\Gamma_{\mathrm{t}}=\frac{\overline{\mathrm{H}}_{\mathrm{t}}}{100-\overline{\mathrm{H}}_{\mathrm{t}}}=\frac{\mathrm{f}_{\mathrm{k}} \cdot \mathrm{I}_{0}(\mathrm{c})-\mathrm{I}_{\mathrm{t}}(\mathrm{c})}{\mathrm{I}_{\mathrm{t}}(\mathrm{c})}
$$

From the results, a linear relationship can be deduced between the function $\Gamma$ and the concentration of the surfactant used, in the following form:

$$
\log (\mathrm{c})=\mathrm{b} \cdot \log (\Gamma)+\log (\mathrm{a})
$$

The values of $\mathrm{EC}_{20}$ and $\mathrm{EC}_{50}$, expressed as $\mathrm{mg} / \mathrm{L}$ are calculated, giving $\Gamma$ values of 0.25 and 1 , respectively. The results for the surfactants assayed are presented in table 1 , for incubation times of 15 and $30 \mathrm{~min}$.

Table 1: Values of $\mathrm{EC}_{50}$ and $\mathrm{EC}_{20} \mathrm{in} \mathrm{mg} / \mathrm{L}$ for Findet $1214 \mathrm{~N} 23$ and NPEO.

\begin{tabular}{|l|c|c|c|c|}
\hline Surfactant & $\mathrm{EC}_{20}(15 \mathrm{~min})$ & $\mathrm{EC}_{50}(15 \mathrm{~min})$ & $\mathrm{EC}_{20}(30 \mathrm{~min})$ & $\mathrm{EC}_{50}(30 \mathrm{~min})$ \\
\hline Findet 1214N23 & 5.54 & 12.67 & 5.93 & 13.26 \\
\hline NPEO & 29.29 & 160.64 & 26.53 & 162.90 \\
\hline
\end{tabular}

To eliminate any doubt concerning the environmental lability of the surfactants, a study was made of the evolution of the toxicity over the biodegradation process. In this way, it can be confirmed whether subproducts of biodegradation are more toxic than the original surfactant, or on the other hand whether the surfactants studied have acceptable environmental biodegradability - that is, the toxicity of the biodegradation metabolites is less than that of the initial surfactant and that the surfactants are not only primarily biodegradable or mineralizable.

For each sample, the luminescence inhibition was measured after $15 \mathrm{~min}$ of incubation, expressing the results as a percentage of inhibition.

Fig. 1 shows the toxicity results during the biodegradation process for the surfactants together with their biodegradation curve.

Fig. 1 shows that the concentration of surfactant in the medium decreases at the same time as the bioluminescence inhibition of the surfactant Findet $1214 \mathrm{~N} / 23$ to any concentration tested, and for NPEO to $5 \mathrm{mg} / \mathrm{L}$. Only for test with NPEO at high concentrations did the bioluminescence inhibition increase during primary biodegradation.

Fig. 2 shows how the inhibition percentage varies with concentration over the biodegradation process. Findet 1214N23 diminished significantly in toxicity during the first few days of the biodegradation assay at all the concentrations tested. Therefore, in general, the metabolites produced during the biodegradation 

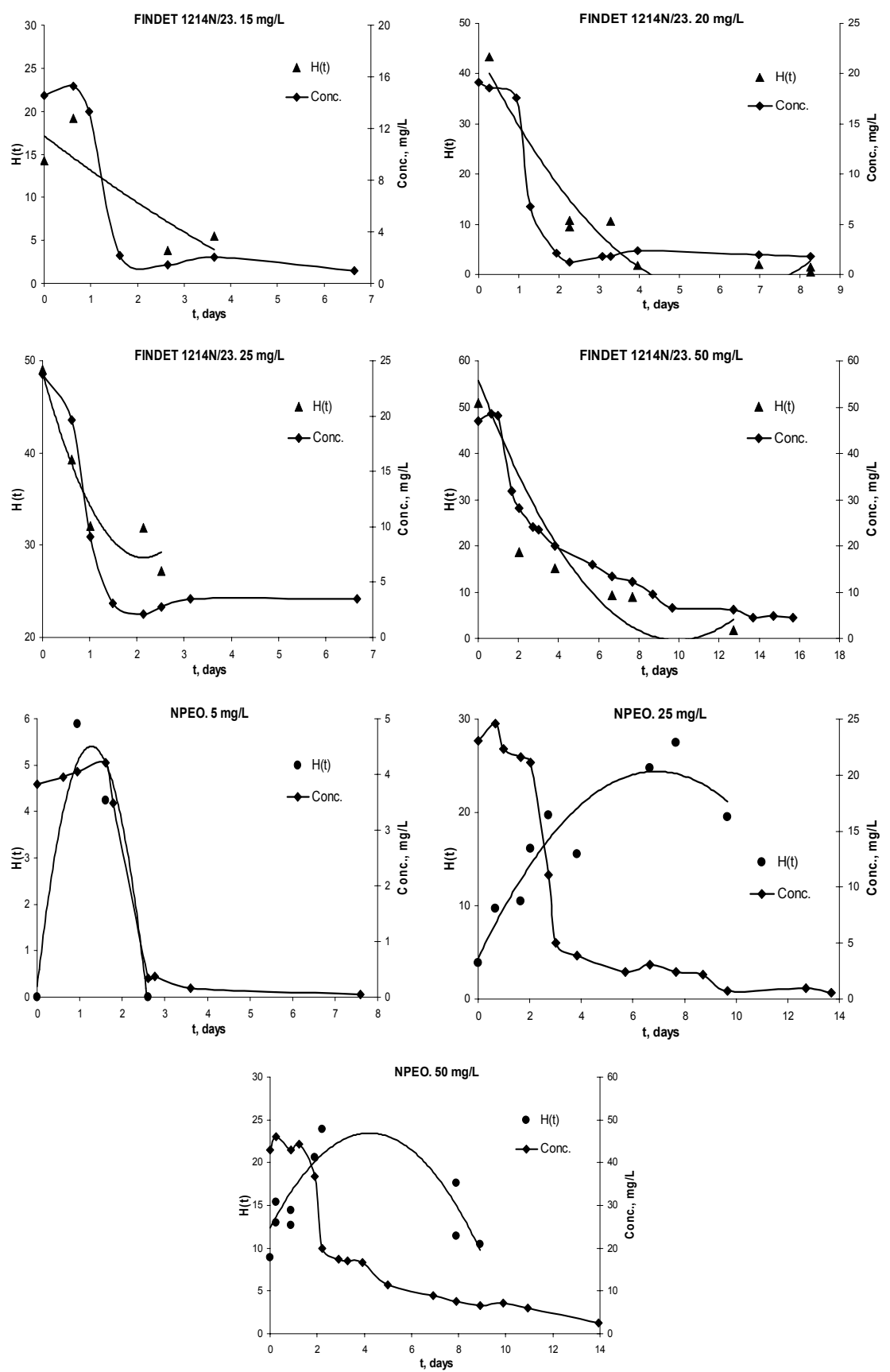

Figure 1: Variation in the percentage of inhibition during the biodegradation process $v s$. biodegradation curve. 
process presented far lower toxicity than the original surfactant and thus can be classified as having acceptable environmental biodegradability. Also, as the surfactant concentration augmented in the assay, more time was needed to reach null toxicity values.
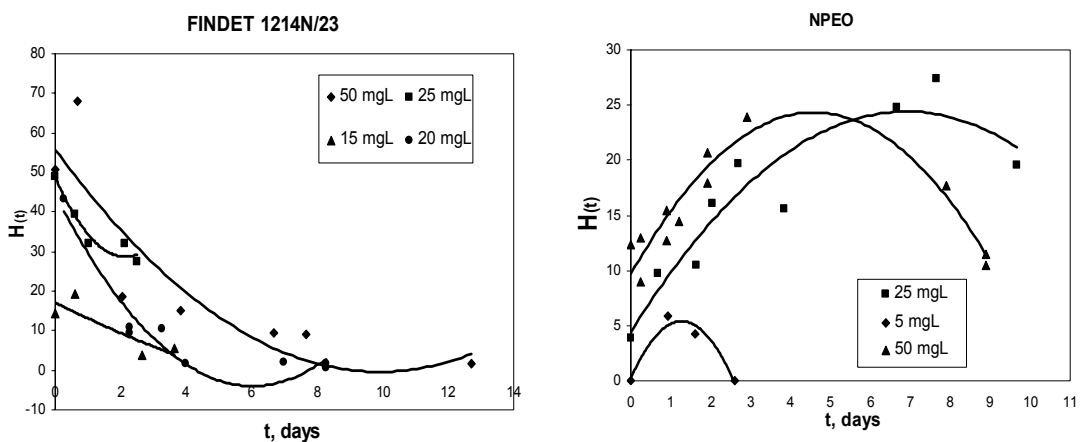

Figure 2: Variation in the percentage of inhibition during the biodegradation process for Findet 1214N23 and NPEO.

For NPEO, the toxicity during the biodegradation process peaked, thus confirming that the biodegradation metabolites were more toxic than the starting compound, as indicated in the literature [8].

\section{Conclusions}

In the study of the environmental lability of two non-ionic surfactants, toxicity values were determined for a fatty alcohol ethoxylate and a nonylphenol polyethoxylate, applying assays with luminescent bacteria using the measurement system LumiStox ${ }^{\circledR} 300$, according to the UNE-EN ISO 11348-2 guideline. The results gave $\mathrm{EC}_{50}(15 \mathrm{~min})$ values of $12.67 \mathrm{mg} / \mathrm{L}$ for the $\mathrm{FAE}$ and $160.64 \mathrm{mg} / \mathrm{L}$ for NPEO. During the biodegradation process, Findet 1214N/23 declined in toxicity $\mathrm{d}$ at all the concentrations tested. However, for the nonylphenol, toxicity peaked during the biodegradation process. This confirms the higher toxicity of the metabolites generated during the biodegradation process, casting doubt on the usefulness of this surfactant for detergent formulas.

\section{References}

[1] Closa, F. X., \& Osset, M., El compromiso medioambiental. Dos ejemplos de la industria de detergentes. Química e industria, 44(1), pp. 16-20, 1997.

[2] E.P. Council, Regulation (EC) No 1907/2006 of the European Parliament and of the Council of 18 December 2006 concerning the Registration, Evaluation, Authorisation and Restriction of Chemicals (REACH), establishing a European Chemicals Agency, amending Directive 
1999/45/EC and repealing Council Regulation (EEC) No 793/93 and Commission Regulation (EC) No 1488/94 as well as Council Directive 76/769/EEC and Commission Directives 91/155/EEC, 93/67/EEC, 93/105/EC and 2000/21/EC, Off. J. Eur. Union 850. 2006.

[3] Prevost, A., Barbeau, J., Cote, L., Charland, R. \& Faucher, E., Patente 5,731, 275 de 24-03-98. Synergistic detergent and disinfectant combinations for decontaminating biofilm-coated surfaces. United States Patent, 1998.

[4] Farré, M., García, M. J., Tirapu, L., Ginebreda, A. \& Barceló D., Wastewater toxicity screening of non-ionic surfactants by Toxalert ${ }^{\circledR}$ and Microtox $^{\circledR}$ bioluminescence inhibition assays. Analytica Chimica Acta, 427, pp. 181-189, 2001.

[5] UNE EN ISO 11348-2 (NORMA UNE EN ISO 11348-2), Determinación del efecto inhibidor de muestras de agua sobre la luminiscencia de Vibrio fischeri (Ensayo de bacterias luminiscentes), 1999.

[6] Jurado, E., Fernández-Serrano M., Núñez-Olea J., Luzón G. \& Lechuga, M., Effect of concentration on the kinetics of primary biodegradation of LAS and toxicity of the biodegradation metabolites. 34 CED's Annual Meetings, 243-252. Barcelona. Spain, 2004.

[7] OECD, Guideline for Testing of Chemicals, "Ready Biodegradability", OECD. Paris. France, 1993.

[8] Marcomini, A., Zanette M., Pojana G. \& Suter M. J., Behavior of aliphatic alcohol polyethoxylates and their metabolites under standardized aerobic biodegradation conditions. Environmental Toxicology and chemistry, 19, pp. 549-554, 2000. 